\title{
The statistical analysis of random-valued impulse noise detection techniques based on the local image characteristic: ROAD, ROLD and RORD
}

\author{
Vorapoj Patanavijit, Kornkamol Thakulsukanant \\ Assumption University, Thailand
}

\begin{tabular}{l}
\hline \hline Article Info \\
\hline Article history: \\
Received Oct 19, 2018 \\
Revised Feb 2, 2019 \\
Accepted Mar 13, 2019
\end{tabular}

Keywords:

Noise detection

Random-valued impulse noise

ROAD

ROLD

RORD

\begin{abstract}
Advances in local image statistical analysis have made possible the randomvalued impulse noise detection but the current noise detections based on ROAD (Rank-Ordered Absolute Differences), ROLD (Rank-Ordered Logarithmic Differences) and RORD (Rank-Ordered Relative Differences), which are the most three effective and practical detections using the local image statistical characteristic, operates effectively on different noise density and different image statistical characteristic. To address these issues, this paper proposes the comparative analysis on the noise detections based on ROAD, ROLD and RORD. Therefore, the first contribution is the comparative statistical distribution of these three noise detections. By comprehensive experiment at each noise density, the optimized detected threshold is later determined from four benchmark data: Lena, Girl, Pepper and Airplane. Moreover, the maximum detection accuracy for each case is comparatively demonstrated by using the noise detections based on ROAD, ROLD and RORD with the optimized detected threshold.
\end{abstract}

Copyright () 2019 Institute of Advanced Engineering and Science. All rights reserved.

\section{Corresponding Author:}

Vorapoj Patanavijit,

Assumption University,

Samut Prakan, Thailand.

Email: Patanavijit@yahoo.com

\section{INTRODUCTION}

Because of communication errors, memory located faulty, malfunctioning CCD sensors, and ADC synchronizing errors, impulse noise [1-4] traditionally contaminates captured digital images. The primary property of this noise [5-21] is that only some group of the pixels is contaminated and another group of the pixels are noiseless. In real implementation, the noise detection [7-21], which is one of the main processes of the image denoising process, is elementary process for forthcoming and advance image process [22-24] such as object classification, face hallucination, car license plate detection, etc. The main objective of noise detection is to classify noisy pixels and noiseless pixels. This section introduces some research documents from the noise detection based on the local image statistical characteristic point of view because the noise detection is one of the most primary processes of the image denoising process and directly impact to the image denoising performance. First, the median filtering (MF) technique [5-7] is used to detect the impulsive noise. Later, the AMF (Adaptive Median Filter) [14, 25] is developed from MF to be noise detected process. Next, the ROAD (Rank-Ordered Absolute Differences) [26], which is the first local image statistical characteristic technique that is used to be image denoising process, has been proposed in 2005. Subsequent, the ROLD (Rank-Ordered Logarithmic Differences) [27], which is developed from ROAD to improve its performance in high noise density, has been proposed in 2007. Finally, the ROAD (Rank-Ordered Relative Differences) [28], which is developed from ROAD and ROLD to improve its performance in low noise density, has been proposed in 2008. Consequently, these three noise detected techniques operates effectively on different noise density and different image statistical characteristic. To address these issues, this paper 
proposes the comparative analysis on the noise detections based on ROAD, ROLD and RORD from the comparative statistical distribution point of view and, moreover, the optimized detected threshold is later determined from four benchmark data: Lena, Girl, Pepper and Airplane by experimenting on several noise density. Furthermore, with the optimized detected threshold, the maximum detection accuracy for each case is comparatively demonstrated by using the noise detections based on ROAD, ROLD and RORD.

\section{RELATED THEORY}

\subsection{Mathematical of Random-Valued Impulse Noise}

Support that the original image is $\mathbf{x}$ where ${ }^{x_{i, j}}$ is the original image pixel at location $(i, j)$ that is $s_{\min } \leq x_{i, j} \leq s_{\max }$ where $\left[s_{\min }, s_{\max }\right]$ is the intensity range of this image. Support that the noisy image is $\mathbf{y}$ where $y_{i, j}$ is the contaminated image pixel at location $(i, j)$, which can be mathematically expressed as following (1):

$$
y_{i, j}=\left\{\begin{array}{cc}
s_{\min } & \text { at probability } p \\
s_{\max } & \text { at probability } q \\
x_{i, j} & \text { at probability }(1-p-q)
\end{array} \text { where }(p-q)\right. \text { is the noise level. }
$$

\subsection{ROAD (Rank-Ordered Absolute Differences) Statistic}

Support that the computed image pixel $y_{i, j}$ at location $(i, j)$ and $\Omega_{N}=\{(s, t) \mid-N \leq s, t \leq N\}$ is its group of neighborhood pixels (with the window size at $(2 N+1) \times(2 N+1)$, which is centered at location $(i, j)$. The ROAD (Rank-Ordered Absolute Differences) Statistic [26] can be mathematically defined as:

$$
\operatorname{ROAD}_{m}(\mathbf{i})=\sum_{i=1}^{m} r_{i}(\mathbf{i})
$$

where $r_{i}(\mathbf{i})=i^{t h}$ smallest $D\left(y_{i, j}\right), \forall(s, t) \in \Omega_{N}$ and $D\left(y_{i, j}\right)$ is defined as the absolute difference between the gray-level intensity $y_{i+s, j+t}$ and $y_{i, j}$ or can be mathematically defined as:

$$
D\left(y_{i, j}\right)=\left|y_{i+s, j+t}-y_{i, j}\right|, \quad \forall(s, t) \in \Omega_{N}
$$

From the simplicity and computational experimental analysis reason [26], this paper defines $m=4$ therefore the ROAD can be mathematically simplified as:

$$
\operatorname{ROAD}_{4}(\mathbf{i})=\sum_{i=1}^{4} r_{i}(\mathbf{i})
$$

In this paper, the normalized ROAD, which is used for analyzing, can be mathematically defined as:

$$
\operatorname{ROAD}_{m}(\mathbf{i})=\frac{1}{m} \sum_{i=1}^{m} r_{i}(\mathbf{i}) \quad \operatorname{ROAD}_{4}(\mathbf{i})=\frac{1}{4} \sum_{i=1}^{4} r_{i}(\mathbf{i})
$$

\subsection{ROLD (Rank-Ordered Logarithmic Differences) Statistic}

In order to detecting noisy pixel and noises pixel under the noise density levels as high as $60 \%$, ROLD statistic technique [27] is desired and developed from ROAD statistic technique and the ROLD (Rank-Ordered Logarithmic Differences) Statistic can be mathematically defined as:

$$
D\left(y_{i, j}\right)=1+\max \left\{\log _{a}\left|y_{i+s, j+t}-y_{i, j}\right|,-b\right\} / b, \forall(s, t) \in \Omega_{N}
$$


From the simplicity and computational experimental analysis reason [27], this paper defines $a=2$ and $b=5$ therefore the ROLD can be mathematically simplified as:

$$
D\left(y_{i, j}\right)=1+\max \left\{\log _{2}\left|y_{i+s, j+t}-y_{i, j}\right|,-5\right\} / 5, \forall(s, t) \in \Omega_{N}
$$

In this paper, the normalized ROLD, which is used for analyzing, can be mathematically defined as:

$$
\operatorname{ROLD}_{m}(\mathbf{i})=\frac{1}{m} \sum_{i=1}^{m} r_{i}(\mathbf{i}) \quad \operatorname{ROLD}_{4}(\mathbf{i})=\frac{1}{4} \sum_{i=1}^{4} r_{i}(\mathbf{i})
$$

\subsection{ROAD (Rank-Ordered Relative Differences) Statistic}

The absolute difference $D\left(y_{i, j}\right)$ between the gray-level intensity $y_{i+s, j+t}$ and $y_{i, j}$ can be usually used for defining whether a computed image pixel $y_{i, j}$ is contaminated by impulse noise. In general, if the absolute difference $D\left(y_{i, j}\right)$ is large then the impulse noise likely contaminates the computed image pixel $y_{i, j}$ however If their neighbor image pixels $y_{i+s, j+t}$ are contaminated but the computed image pixel $y_{i, j}$ is noiseless then the absolute difference $D\left(y_{i, j}\right)$ is large or if the computed window contains a sharp edge texture then the absolute difference $D\left(y_{i, j}\right)$ is large. In order to improve the performance of noisy/noiseless detected rate, the RORD statistic technique [28], which is desired and developed from ROAD statistic technique by using a reference image, can be mathematically defined as:

$$
\begin{aligned}
& D\left(y_{i, j}\right)=\left|\hat{y}_{i+s, j+t}-\hat{y}_{i, j}\right|, \quad \forall(s, t) \in \Omega_{N} \\
& \hat{\mathbf{y}}=\mathbf{y}-\alpha \times \mathbf{y}_{\text {ref }}
\end{aligned}
$$

From the simplicity and computational experimental analysis reason [28], the reference image $\mathbf{y}_{\text {ref }}$ in this paper is computed from the contaminated image by filtering by MF (median filter) denoising process and $\alpha$ is usually set to be 0.5 .

In this paper, the normalized RORD, which is used for analyzing, can be mathematically defined as:

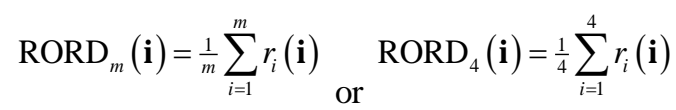

\section{COMPARATIVE EXPERIMENTAL RESULTS}

\subsection{The Simulated Estimation of Optimized Noise Threholds}

First, this experiment investigates the statistical distribution of the noisy and noiseless pixels of the ROAD, ROLD and RORD by using four benchmark data: Airplane, Girl, Lena, and Pepper under many impulse noise densities (from 5\% to 90\%) as shown in Figure 1 to Figure 4, respectively. Then, the optimized thresholds for classifying noisy and noiseless pixels are estimated for each image at each noise density from the maximum detection accuracy perspective. The noise detection accuracy is defined as:

$$
\text { Accuracy }=\frac{1}{2}\left(\frac{\text { number of estimated noisy pixels }}{\text { number of noisy pixels }}\right)+\frac{1}{2}\left(\frac{\text { number of estimated noiseless pixels }}{\text { number of noiseless pixels }}\right)
$$

\subsection{The Simulated Results of Noise Detection Accuracy}

Later, by using the optimized thresholds for classifying noisy and noiseless pixels, this experiment investigates the noise detection accuracy of the ROAD, ROLD and RORD by using four benchmark data: Airplane, Girl, Lena, and Pepper under many impulse noise densities (from 5\% to 90\%) as shown in Table 1 to Table 4, respectively. From this experimental result, the RORD has the highest noise detection accuracy 
under low impulse noise densities $(<40 \%)$ but the ROLD has the highest noise detection accuracy under high impulse noise densities (> 60\%). The ROAD usually has lower noise detection accuracy than ROLD and RORD in almost all cases because both ROLD and RORD are developed and modified from ROAD. Compared to AMF (Adaptive Median Filter) [14, 25], the ROAD, ROLD and RORD has higher noise detection accuracy because the AMF is desired for Salt\&Pepper noise.

Table 1. The Noise Detection Performance: Airplain

\begin{tabular}{|c|c|c|c|c|c|c|c|c|c|c|c|c|c|c|c|c|c|c|}
\hline \multirow{2}{*}{$\begin{array}{c}\text { Noise } \\
\text { Detection } \\
\text { Tech. }\end{array}$} & \multicolumn{18}{|c|}{ Impulse Noise Density (\%) } \\
\hline & 5 & 10 & 15 & 20 & 25 & 30 & 35 & 40 & 45 & 50 & 55 & 60 & 65 & 70 & 75 & 80 & 85 & 90 \\
\hline \multirow{2}{*}{$\mathrm{AMF}$} & 0.81 & 0.78 & 0.75 & 0.72 & 0.70 & 0.68 & 0.66 & 0.64 & 0.62 & 0.61 & 0.60 & 0.59 & 0.58 & 0.57 & 0.56 & 0.56 & 0.55 & 0.55 \\
\hline & 54 & 31 & 11 & 74 & 61 & 47 & 17 & 49 & 82 & 83 & 75 & 57 & 70 & 83 & 97 & 28 & 83 & 25 \\
\hline \multirow{2}{*}{ ROAD } & 0.91 & 0.91 & 0.91 & 0.91 & 0.91 & 0.91 & 0.90 & 0.89 & 0.89 & 0.88 & 0.87 & 0.86 & 0.85 & 0.84 & 0.84 & 0.83 & 0.83 & 0.82 \\
\hline & 90 & 73 & 71 & 78 & 41 & 09 & 68 & 92 & 28 & 47 & 59 & 68 & 70 & 87 & 33 & 88 & 51 & 98 \\
\hline \multirow{2}{*}{ ROLD } & 0.91 & 0.91 & 0.91 & 0.91 & 0.91 & 0.91 & 0.90 & 0.90 & 0.89 & 0.89 & 0.88 & 0.87 & 0.86 & 0.85 & 0.85 & 0.84 & 0.84 & 0.83 \\
\hline & 97 & 64 & 66 & 79 & 46 & 14 & 85 & 21 & 71 & 01 & 42 & 79 & 79 & 83 & 12 & 63 & 16 & 70 \\
\hline RORD & 01 & 63 & 52 & 33 & 85 & 18 & 60 & 57 & 92 & 76 & 94 & 77 & 63 & 69 & 07 & 47 & 08 & 70 \\
\hline
\end{tabular}

Table 2. The Noise Detection Performance: Girl

\begin{tabular}{|c|c|c|c|c|c|c|c|c|c|c|c|c|c|c|c|c|c|c|}
\hline \multirow{2}{*}{$\begin{array}{c}\text { Noise } \\
\text { Detectio } \\
\text { n Tech. }\end{array}$} & \multicolumn{18}{|c|}{ Impulse Noise Density (\%) } \\
\hline & 5 & 10 & 15 & 20 & 25 & 30 & 35 & 40 & 45 & 50 & 55 & 60 & 65 & 70 & 75 & 80 & 85 & 90 \\
\hline \multirow{2}{*}{$\mathrm{AMF}$} & 0.73 & 0.69 & 0.65 & 0.62 & 0.58 & 0.56 & 0.53 & 0.52 & 0.50 & 0.48 & 0.46 & 0.45 & 0.43 & 0.42 & 0.40 & 0.39 & 0.38 & 0.37 \\
\hline & 63 & 10 & 58 & 09 & 80 & 32 & 81 & 17 & 21 & 27 & 77 & 16 & 78 & 41 & 96 & 55 & 31 & 12 \\
\hline \multirow{2}{*}{ ROAD } & 0.93 & 0.93 & 0.93 & 0.93 & 0.93 & 0.93 & 0.92 & 0.91 & 0.91 & 0.90 & 0.89 & 0.88 & 0.87 & 0.86 & 0.86 & 0.85 & 0.84 & 0.84 \\
\hline & 81 & 57 & 84 & 83 & 62 & 02 & 47 & 96 & 27 & 33 & 57 & 57 & 59 & 93 & 04 & 24 & 67 & 20 \\
\hline \multirow{2}{*}{ ROLD } & 0.93 & 0.93 & 0.93 & 0.93 & 0.93 & 0.93 & 0.92 & 0.92 & 0.92 & 0.91 & 0.90 & 0.89 & 0.88 & 0.88 & 0.87 & 0.86 & 0.86 & 0.85 \\
\hline & 85 & 49 & 87 & 78 & 67 & 15 & 65 & 37 & 06 & 32 & 76 & 86 & 94 & 26 & 42 & 62 & 09 & 60 \\
\hline \multirow{2}{*}{ RORD } & 0.94 & 0.93 & 0.94 & 0.93 & 0.93 & 0.92 & 0.91 & 0.91 & 0.90 & 0.88 & 0.87 & 0.86 & 0.84 & 0.83 & 0.82 & 0.81 & 0.80 & 0.79 \\
\hline & 60 & 99 & 03 & 84 & 37 & 62 & 81 & 15 & 19 & 86 & 88 & 22 & 78 & 61 & 23 & 07 & 02 & 43 \\
\hline
\end{tabular}

Table 3. The Noise Detection Performance: Lena

\begin{tabular}{|c|c|c|c|c|c|c|c|c|c|c|c|c|c|c|c|c|c|c|}
\hline \multirow{2}{*}{$\begin{array}{c}\text { Noise } \\
\text { Detectio } \\
\text { n Tech. }\end{array}$} & \multicolumn{18}{|c|}{ Impulse Noise Density (\%) } \\
\hline & 5 & 10 & 15 & 20 & 25 & 30 & 35 & 40 & 45 & 50 & 55 & 60 & 65 & 70 & 75 & 80 & 85 & 90 \\
\hline \multirow{2}{*}{ AMF } & 0.83 & 0.81 & 0.78 & 0.76 & 0.74 & 0.72 & 0.70 & 0.69 & 0.67 & 0.66 & 0.64 & 0.63 & 0.63 & 0.61 & 0.61 & 0.60 & 0.59 & 0.59 \\
\hline & 95 & 33 & 96 & 50 & 28 & 33 & 49 & 20 & 73 & 24 & 86 & 73 & 02 & 92 & 15 & 40 & 73 & 09 \\
\hline \multirow{2}{*}{ ROAD } & 0.94 & 0.91 & 0.91 & 0.90 & 0.90 & 0.90 & 0.89 & 0.89 & 0.88 & 0.87 & 0.86 & 0.86 & 0.85 & 0.84 & 0.84 & 0.83 & 0.83 & 0.82 \\
\hline & 95 & 06 & 26 & 97 & 45 & 20 & 71 & 01 & 34 & 69 & 67 & 05 & 47 & 62 & 05 & 38 & 05 & 63 \\
\hline \multirow{2}{*}{ ROLD } & 0.95 & 0.90 & 0.91 & 0.90 & 0.90 & 0.90 & 0.90 & 0.89 & 0.88 & 0.88 & 0.87 & 0.86 & 0.86 & 0.85 & 0.84 & 0.83 & 0.83 & 0.82 \\
\hline & 15 & 98 & 28 & 87 & 45 & 36 & 00 & 54 & 99 & 56 & 53 & 81 & 06 & 12 & 54 & 84 & 33 & 87 \\
\hline \multirow{2}{*}{ RORD } & 0.95 & 0.92 & 0.92 & 0.91 & 0.90 & 0.90 & 0.89 & 0.89 & 0.88 & 0.87 & 0.86 & 0.85 & 0.85 & 0.84 & 0.83 & 0.83 & 0.83 & 0.82 \\
\hline & 39 & 33 & 02 & 65 & 88 & 40 & 98 & 29 & 59 & 88 & 72 & 91 & 28 & 48 & 87 & 41 & 05 & 64 \\
\hline
\end{tabular}

Table 4. The Noise Detection Performance: Pepper

\begin{tabular}{|c|c|c|c|c|c|c|c|c|c|c|c|c|c|c|c|c|c|c|}
\hline \multirow{2}{*}{$\begin{array}{c}\text { Noise } \\
\text { Detecti } \\
\text { on } \\
\text { Tech. }\end{array}$} & \multicolumn{18}{|c|}{ Impulse Noise Density (\%) } \\
\hline & 5 & 10 & 15 & 20 & 25 & 30 & 35 & 40 & 45 & 50 & 55 & 60 & 65 & 70 & 75 & 80 & 85 & 90 \\
\hline \multirow{2}{*}{$\mathrm{AMF}$} & 0.85 & 0.81 & 0.78 & 0.76 & 0.73 & 0.71 & 0.70 & 0.68 & 0.66 & 0.65 & 0.64 & 0.62 & 0.61 & 0.60 & 0.59 & 0.59 & 0.58 & 0.58 \\
\hline & 50 & 89 & 93 & 38 & 68 & 91 & 02 & 19 & 53 & 39 & 11 & 63 & 76 & 73 & 82 & 07 & 63 & 03 \\
\hline \multirow{2}{*}{ ROAD } & 0.91 & 0.91 & 0.91 & 0.90 & 0.90 & 0.90 & 0.89 & 0.89 & 0.88 & 0.87 & 0.86 & 0.85 & 0.85 & 0.84 & 0.83 & 0.82 & 0.82 & 0.82 \\
\hline & 69 & 28 & 26 & 72 & 65 & 24 & 95 & 04 & 15 & 28 & 88 & 93 & 23 & 43 & 66 & 90 & 83 & 46 \\
\hline \multirow{2}{*}{ ROLD } & 0.91 & 0.91 & 0.91 & 0.90 & 0.90 & 0.90 & 0.90 & 0.89 & 0.88 & 0.88 & 0.87 & 0.86 & 0.85 & 0.85 & 0.84 & 0.83 & 0.83 & 0.82 \\
\hline & 53 & 15 & 24 & 75 & 71 & 37 & 22 & 39 & 83 & 00 & 61 & 75 & 95 & 05 & 16 & 34 & 17 & 78 \\
\hline \multirow{2}{*}{ RORD } & 0.92 & 0.92 & 0.91 & 0.91 & 0.90 & 0.90 & 0.89 & 0.89 & 0.88 & 0.87 & 0.86 & 0.85 & 0.84 & 0.83 & 0.82 & 0.82 & 0.82 & 0.81 \\
\hline & 99 & 17 & 93 & 39 & 96 & 35 & 89 & 00 & 16 & 16 & 56 & 36 & 50 & 64 & 78 & 12 & 05 & 82 \\
\hline
\end{tabular}

\section{EXPERIMENTAL SUMMARY}

This paper presents the comparative analysis on the noise detections based on ROAD, ROLD and RORD. Therefore, the first contribution is the comparative statistical distribution of these three noise detections. By comprehensive experiment at each noise density, the optimized detected threshold is later 
determined from four benchmark data: Lena, Girl, Pepper and Airplane. Seond, the maximum detection accuracy for each case is comparatively demonstrated by using the noise detections based on ROAD, ROLD and RORD with the optimized detected threshold.

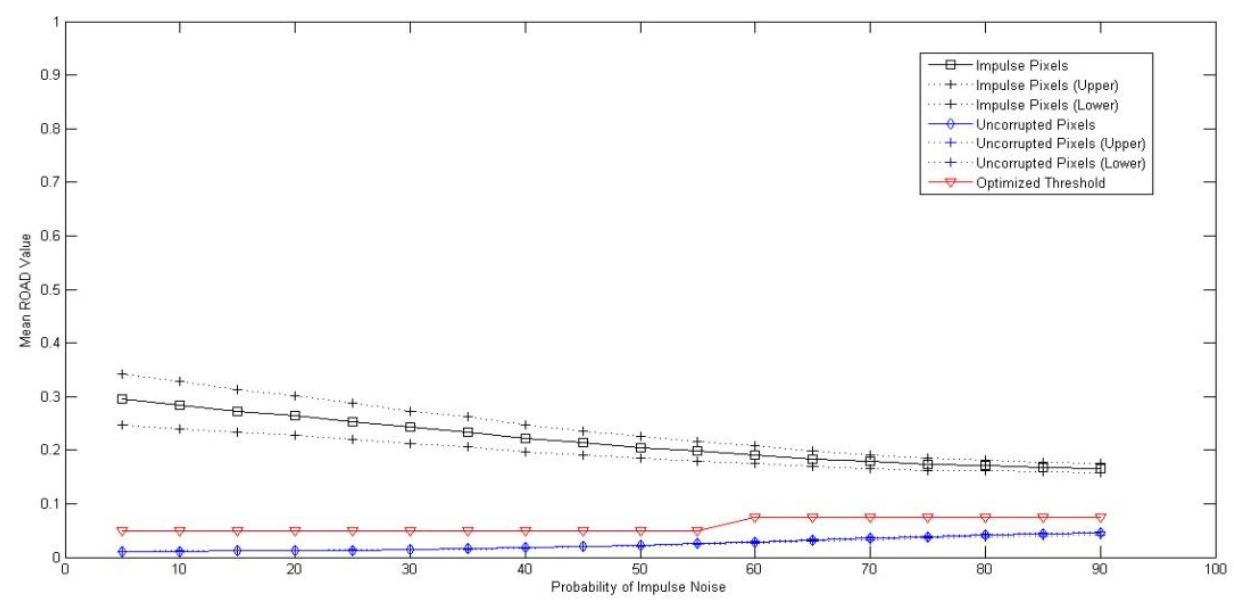

Figure 1(a). Mean ROAD of noisy/noiseless pixels: Airplane

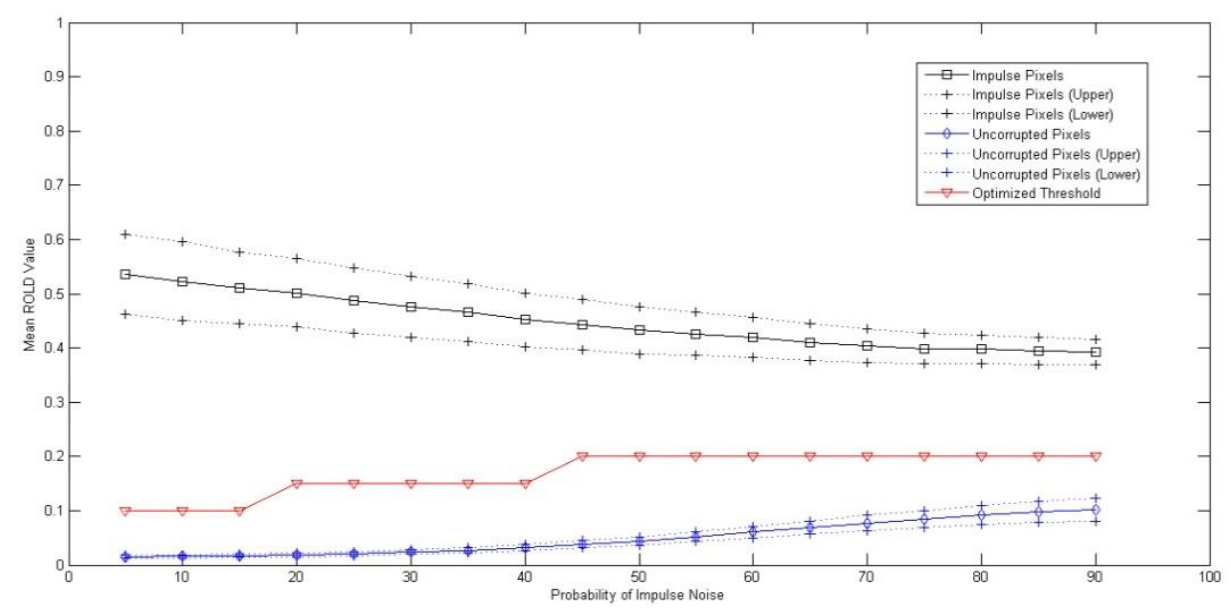

Figure 1(b). Mean ROLD of noisy/noiseless pixels: Airplane

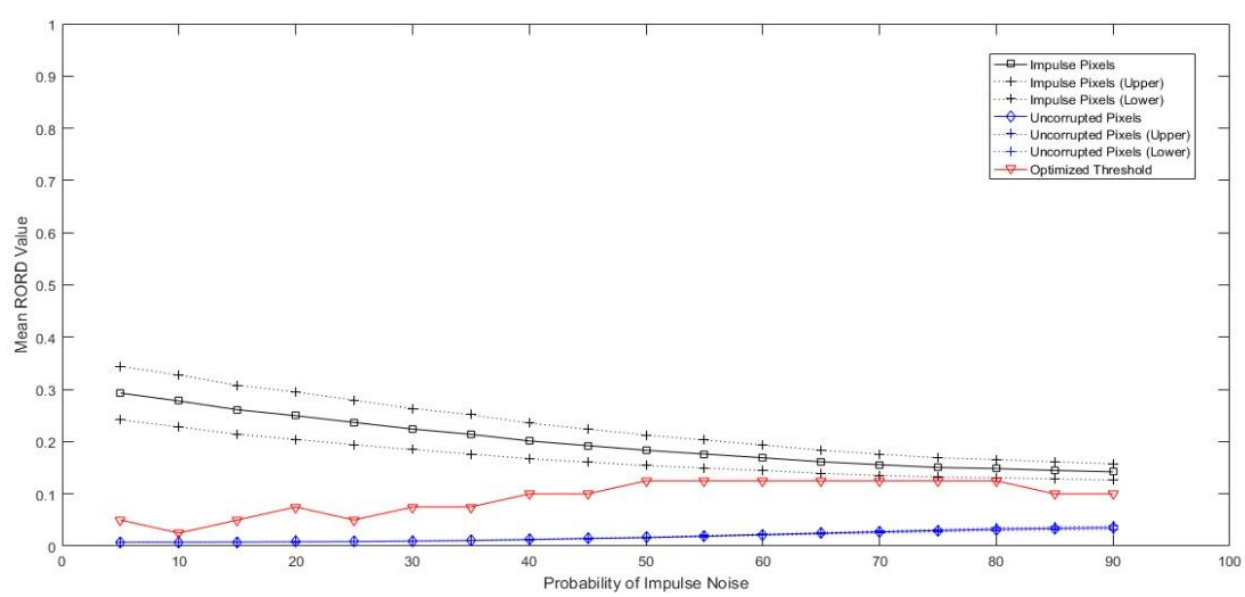

Figure 1(c). Mean RORD of noisy/noiseless pixels: Airplane 


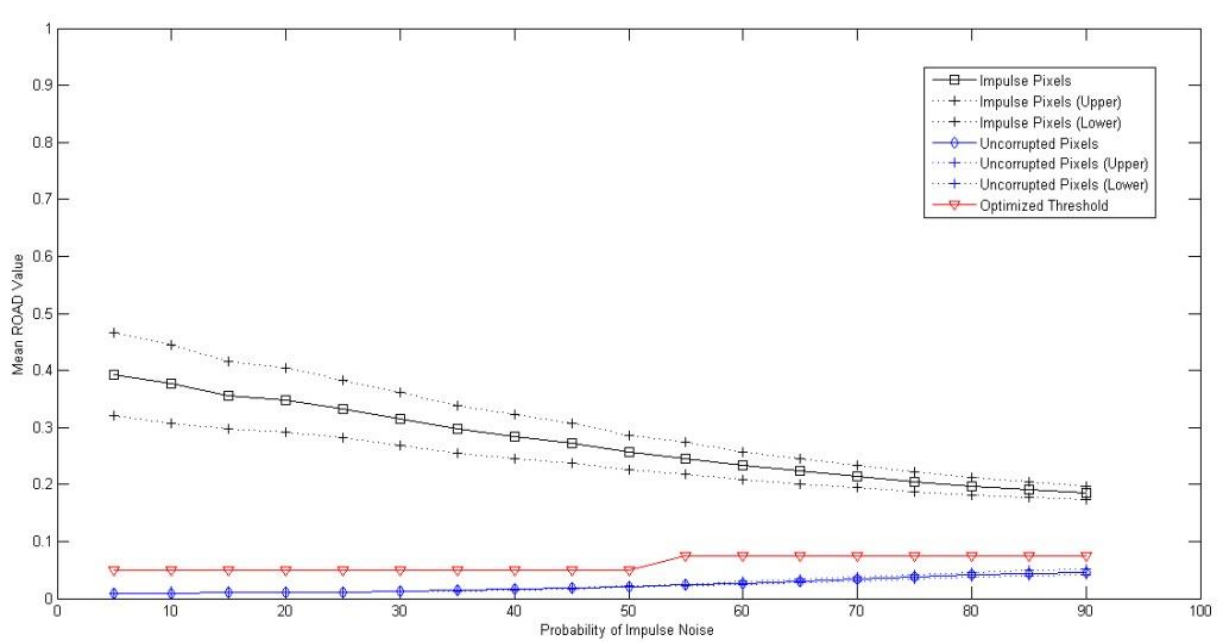

Figure 2(a). Mean ROAD of noisy/noiseless pixels: Girl

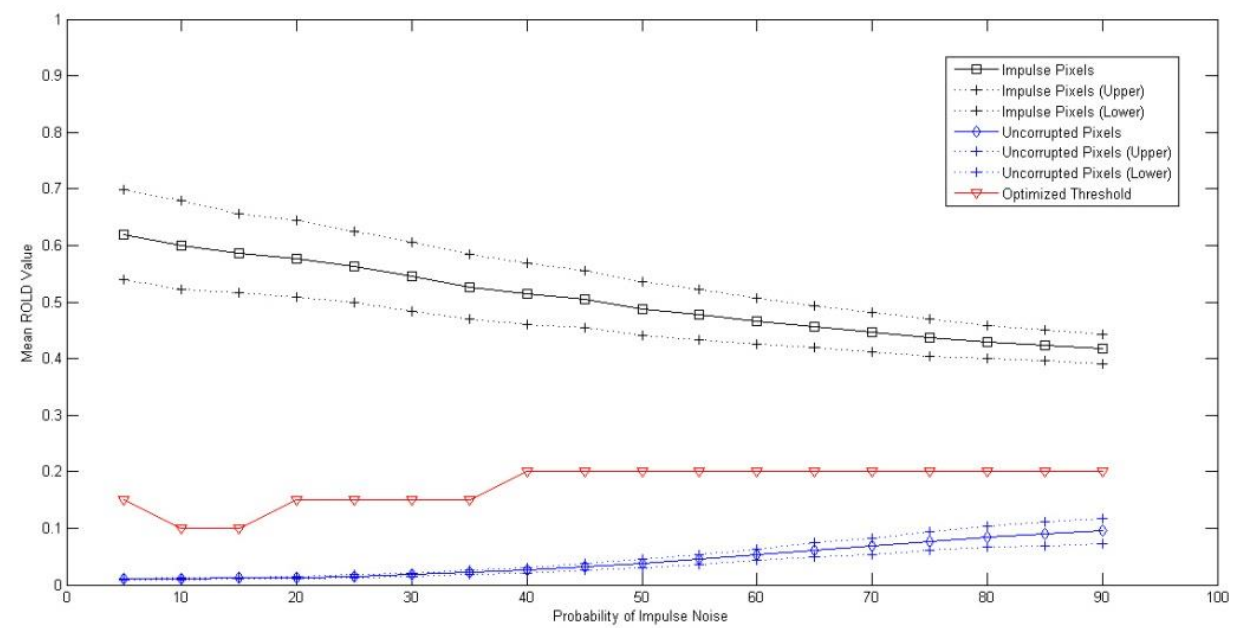

Figure 2(b). Mean ROLD of noisy/noiseless pixels: Girl

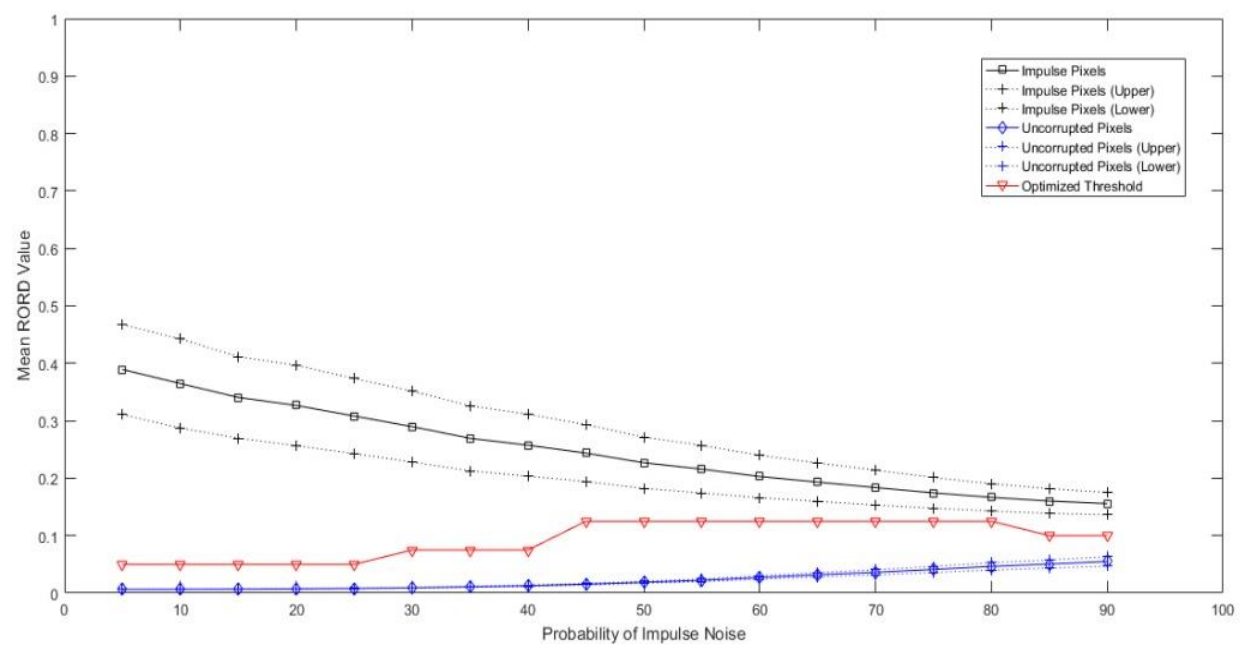

Figure 2(c). Mean RORD of noisy/noiseless pixels: Girl 


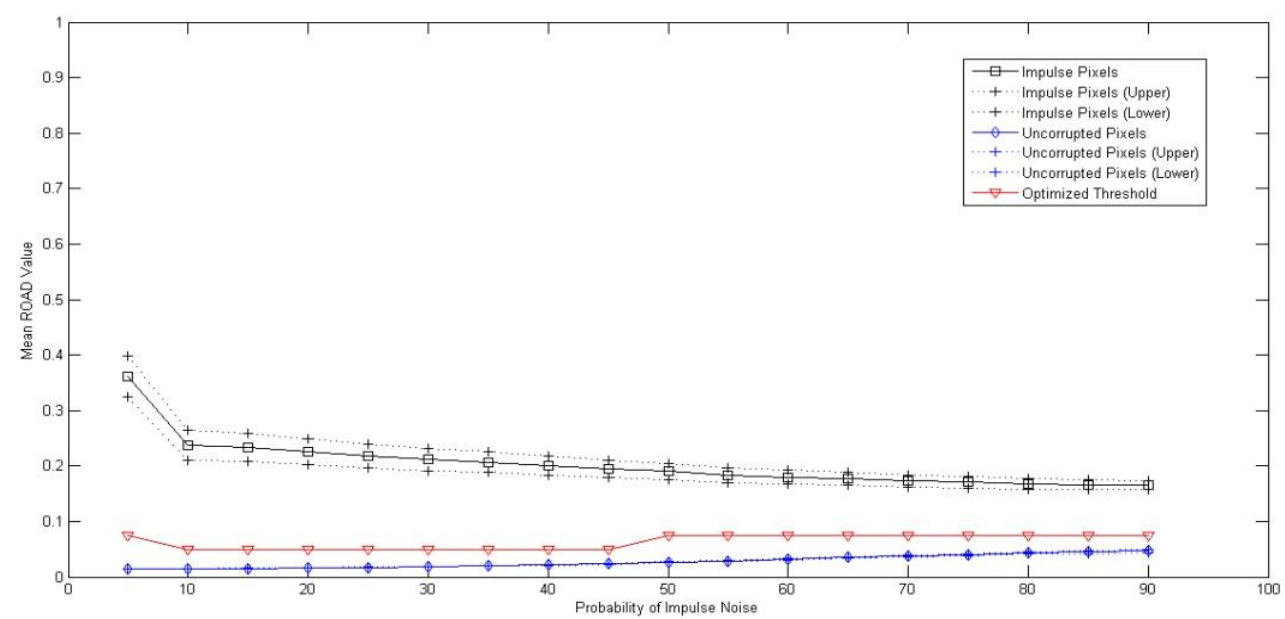

Figure 3(a). Mean ROAD of noisy/noiseless pixels: LENA

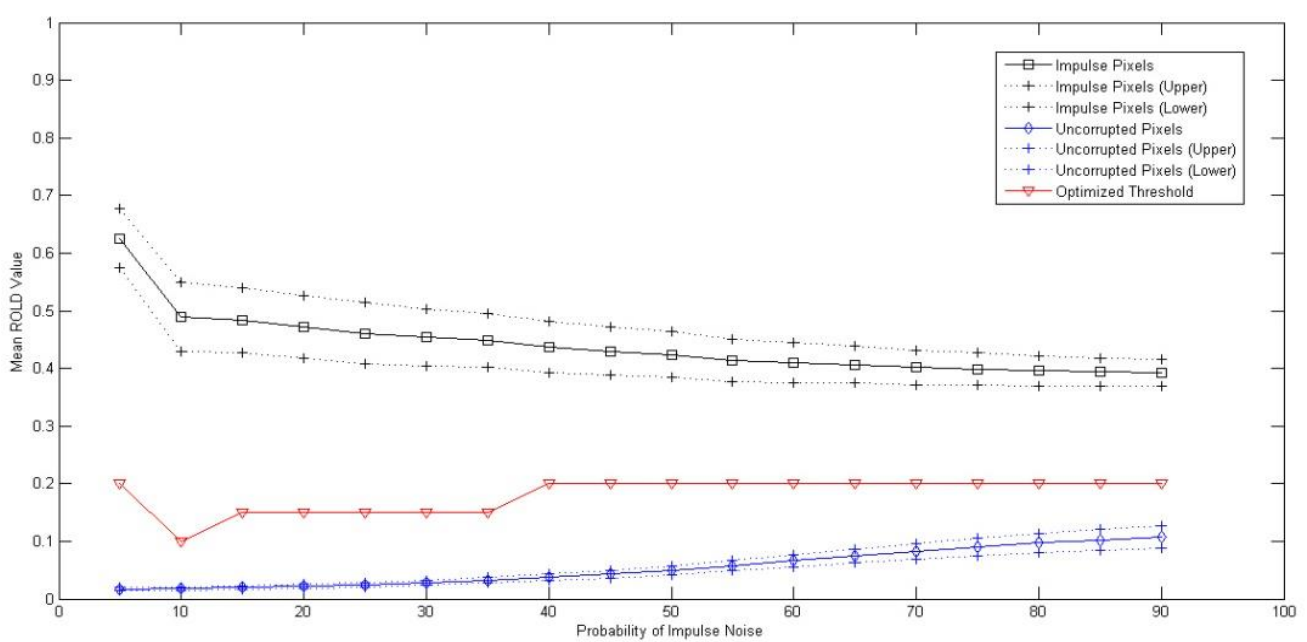

Figure 3(b). Mean ROLD of noisy/noiseless pixels: LENA

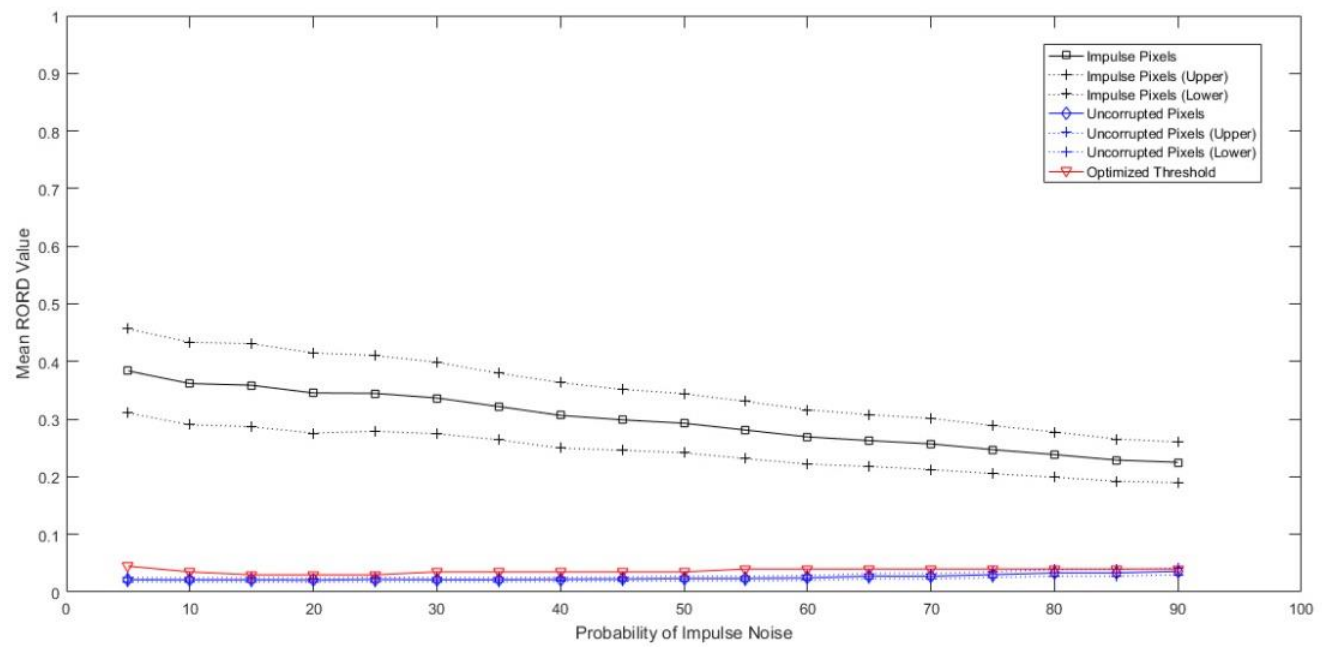

Figure 3(c). Mean RORD of noisy/noiseless pixels: LENA 


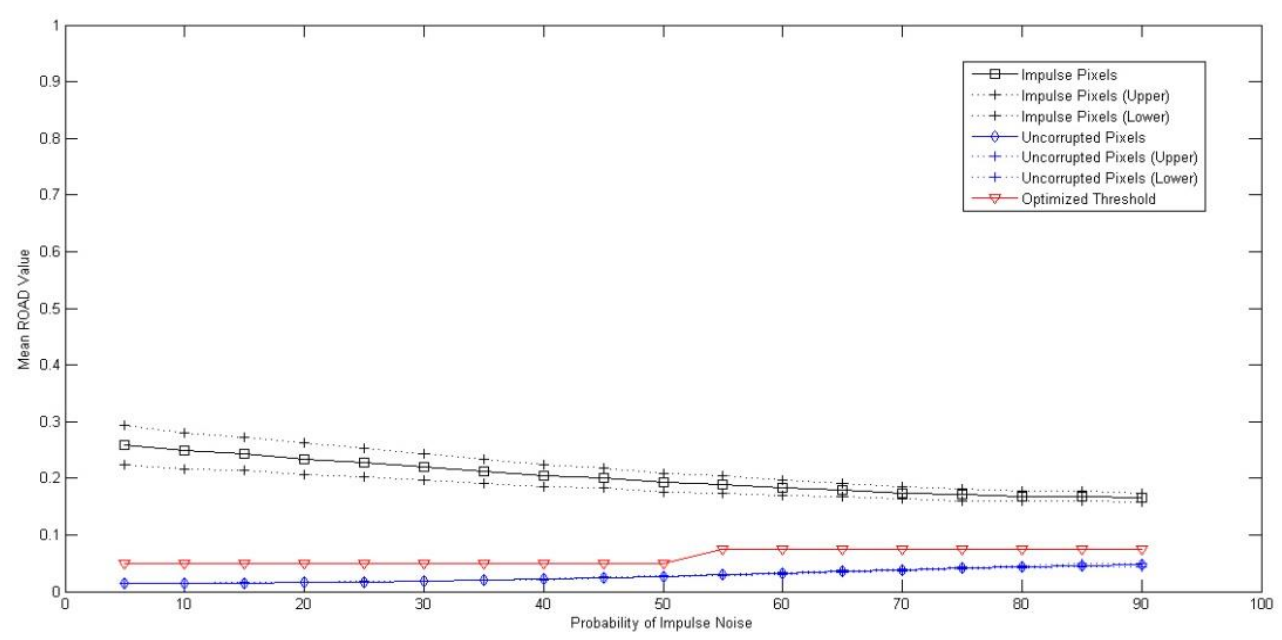

Figure 4(a). Mean ROAD of noisy/noiseless pixels: Pepper

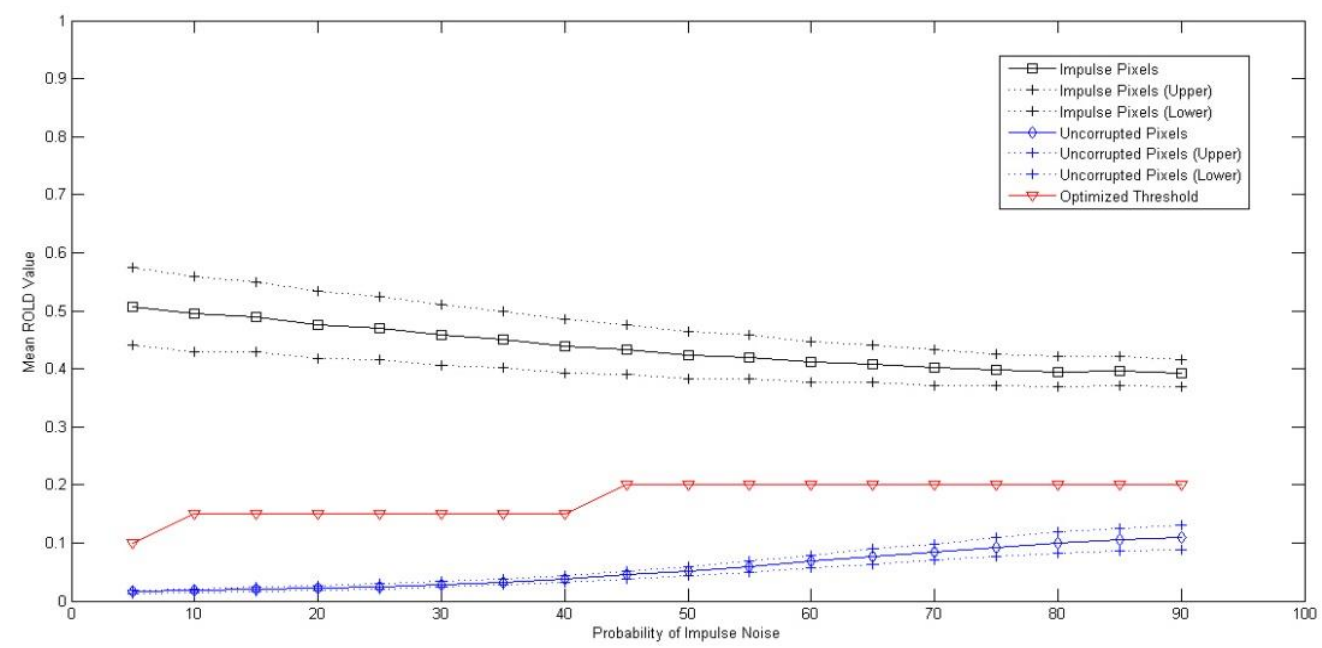

Figure 4(b). Mean ROLD of noisy/noiseless pixels: Pepper

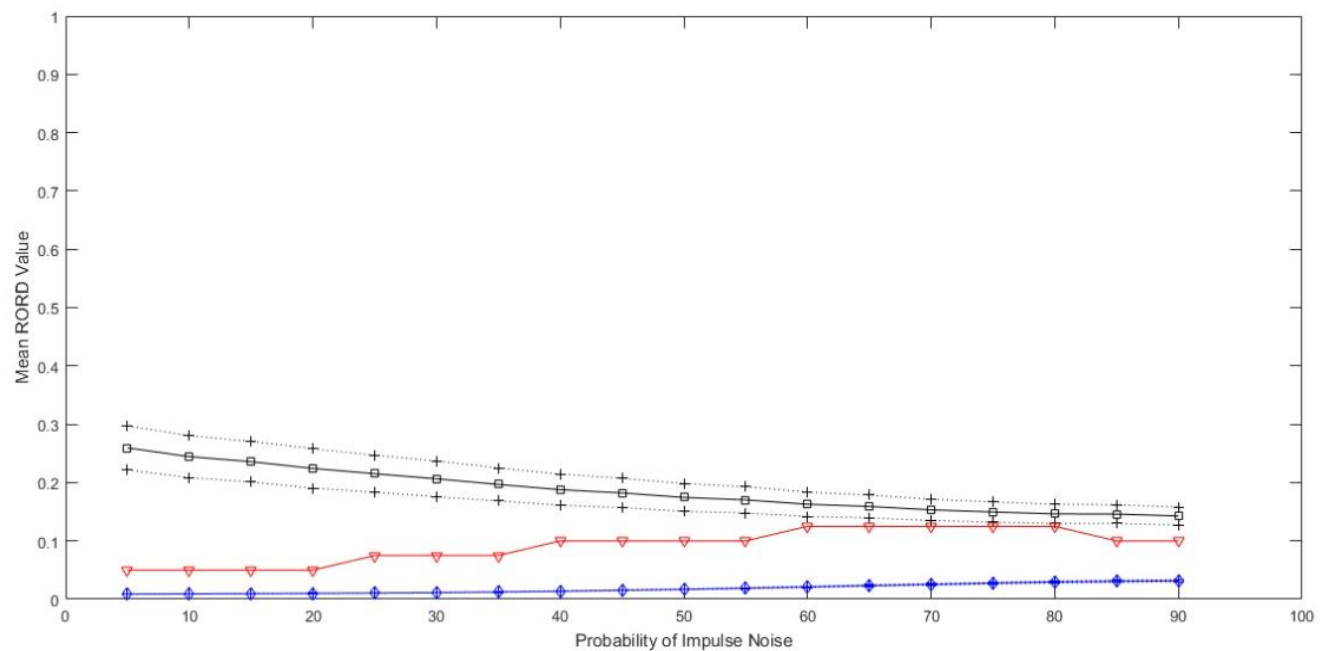

Figure 4(c). Mean RORD of noisy/noiseless pixels: Pepper 


\section{ACKNOWLEDGEMENTS}

The research project was funded by Assumption University.

\section{REFERENCES}

[1] I. Pitas and A. N. Venetsanopoulos, "Nonlinear Digital Filters Principles and Applications", Kluwer Academic Publishers, Norwell, Mass, USA, 1990.

[2] J. Astola and P. Kuosmanen, "Fundamentals of Nonlinear Digital Filtering", CRC Press, Boca Raton, Fla, USA, 1997.

[3] R. C. Gonzalez and R. E. Woods, "Digital Image Processing, Prentice-Hall”, Upper Saddle River,NJ, USA, 2nd edition, 2002.

[4] M. H. Hayes, "Statistical Digital Signal Processing and Modeling”, JohnWiley \& Sons, Singapore, 2002.

[5] W. K. Pratt, "Median filtering," Tech. Rep., Image Proc. Inst., Univ. Southern California, Los Angeles, Sep. 1975.

[6] N. C. Gallagher Jr. and G. L.Wise, "A Theoretical Analysis of the Properties of Median Filters," IEEE Transactions on Acoustics, Speech, and Signal Processing, vol. 29, no. 6, pp. 1136-1141, 1981.

[7] T. A. Nodes and N. C. Gallagher Jr., "Median Filters: Some Modifications and Their Properties," IEEE Transactions on Acoustics, Speech, and Signal Processing, vol. 30, no. 5, pp. 739-746, 1982.

[8] E. Abreu, M. Lightstone, S. K. Mitra, and K. Arakawa, "A New Efficient Approach for the Removal of Impulse Noise from Highly Corrupted Images," IEEE Transactions on Image Processing, vol. 5, no. 6, pp. 1012-1025, 1996.

[9] D. R. K. Brownrigg, "The Weighted Median Filter," Communications of the ACM, vol. 27, no. 8, pp. 807-818, 1984.

[10] O. Yli-Harja, J. Astola, and Y. Neuvo, "Analysis of the Properties of Median and Weighted Median Filters using Threshold Logic and Stack Filter Representation," IEEE Transactions on Signal Processing, vol. 39, no. 2, pp. 395-410, 1991.

[11] G. R. Arce and J. L. Paredes, "Recursive Weighted Median Filters Admitting Negative Weights and Their Optimization," IEEE Transactions on Signal Processing, vol. 48, no. 3, pp. 768-779, 2000.

[12] Y. Dong and S. Xu, "A New Directional Weighted Median Filter for Removal of Random-Valued Impulse Noise," IEEE Signal Processing Letters, vol. 14, no. 3, pp. 193-196, 2007.

[13] T. Chen, K.-K.Ma, and L.-H. Chen, "Tri-State Median Filter for Image Denoising," IEEE Transactions on Image Processing, vol. 8, no. 12, pp. 1834-1838, 1999.

[14] H. Hwang and R. A. Haddad, "Adaptive Median Filters: New Algorithms and Results," IEEE Transactions on Image Processing, vol. 4, no. 4, pp. 499-502, 1995.

[15] S. Zhang and M. A. Karim, "A New Impulse Detector for Switching Median Filters," IEEE Signal Processing Letters, vol. 9, no. 11, pp. 360-363, 2002.

[16] H.-L. Eng and K.-K. Ma, "Noise Adaptive Soft-Switching Median Filter," IEEE Transactions on Image Processing, vol. 10, no. 2, pp. 242-251, 2001.

[17] Z. Wang and D. Zhang, "Progressive Switching Median Filter for the Removal of Impulse Noise from Highly Corrupted Images," IEEE Transactions on Circuits and Systems II, vol. 46, no. 1, pp. 78-80, 1999.

[18] P.-E. Ng and K.-K.Ma, "A Switching Median Filter with Boundary Discriminative Noise Detection for Extremely Corrupted Images," IEEE Transactions on Image Processing, vol. 15, no. 6, pp. 1506-1516, 2006.

[19] R. H. Chan, C.-W. Ho, and M. Nikolova, "Salt-and-Pepper Noise Removal by Median-Type Noise Detectors and Detailpreserving Regularization," IEEE Transactions on Image Processing, vol. 14, no. 10, pp. 1479-1485, 2005.

[20] K. S. Srinivasan and D. Ebenezer, "A New Fast and Efficient Decision-Based Algorithm for Removal of HighDensity Impulse Noises,” IEEE Signal Processing Letters, vol. 14, no. 3, pp. 189-192, 2007.

[21] S. Schulte, M. Nachtegael, V. DeWitte, D. van der Weken, and E. E. Kerre, "A Fuzzy Impulse Noise Detection and Reduction Method," IEEE Transactions on Image Processing, vol. 15, no. 5, pp. 1153-1162, 2006.

[22] Raden Arief Setyawan, Rudy Sunoko, Mochammad Agus Choiron, Panca Mudji Rahardjo, "Implementation of Stereo Vision Semi-Global Block Matching Methods for Distance Measurement", Indonesian Journal of Electrical Engineering and Computer Science(IJEECS), Vol. 12, No. 2, November 2018, pp. 585-591.

[23] Vorapoj Patanavijit, "Performance Analysis of Denoising Algorithm Based on Adaptive Median Filter Under Unsystematic Intensity Impulse and Salt\&Pepper Noise", The 6th International Electrical Engineering Congress (iEECON2017), Krabi, Thailand, March 2018.

[24] V. Jayaraj and D. Ebenezer, "A New Switching-BasedMedian Filtering Scheme and Algorithm for Removal of High-Density Salt and Pepper Noise in Images", EURASIP Journal on Advances in Signal Processing, Hindawi Publishing Corporation, 2010

[25] Vorapoj Patanavijit, "Performance Analysis of Denoising Algorithm Based on Adaptive Median Filter Under Unsystematic Intensity Impulse and Salt\&Pepper Noise", The 6th International Electrical Engineering Congress (iEECON2017), Krabi, Thailand, March 2018. (IEEE Xplore)

[26] Roman Garnett, Timothy Huegerich, Charles Chui, and Wenjie He, "A Universal Noise Removal Algorithm with an Impulse Detector", IEEE Transactions on Image Processing, Vol. 14, No. 11, Nov. 2005.

[27] Yiqiu Dong, Raymond H. Chan, and Shufang Xu, "A Detection Statistic for Random-Valued Impulse Noise", IEEE Transactions on Image Processing, Vol. 16, No. 4, April 2007.

[28] Hancheng Yu, Li Zhao and Haixian Wang, "An Efficient Procedure for Removing Random-Value Impulse Nose in Image”, IEEE Signal Processing Letters, Vol. 15, 2008. 


\section{BIOGRAPHIES OF AUTHORS}

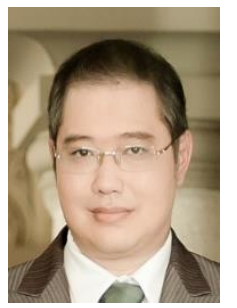

Vorapoj Patanavijit received the B.Eng., M.Eng. and Ph.D. degrees from the Department of Electrical Engineering at the Chulalongkorn University, Bangkok, Thailand, in 1994, 1997 and 2007 respectively. He has served as a full-time lecturer at Department of Electrical and Electronic Engineering, Faculty of Engineering, Assumption University since 1998 where he is currently an Associate Professor. He has authored and co-authored over 150 national/international peer-reviewed publications in Digital Signal Processing (DSP) and Digital Image Processing (DIP). He received the best paper awards from many conferences such as ISCIT2006, NCIT2008, EECON-33 (2010), EECON-34 (2011), EECON-35 (2012) and etc. Moreover, he is invited to be the guest speaker at IWAIT2014 and contributed the invited paper at iEECON 2014. He has served as a Technical Program Committees (TPC) on Signal Processing of ECTI (Electrical Engineering/Electronics, Computer, Telecommunications and Information Technology) Association, Thailand since 2012 to 2015. As a technical reviewer of international journals since 2006, he has been assigned to review over 60 journal papers (indexed by ISI) from IEEE Transactions on Image Processing, IEEE Journal of Selected Topics in Signal Processing (J-STSP), IET in Image Processing (IEEE), IEEE Signal Processing Letters (IEEE), EURASIP Journal on Applied Signal Processing (JASP), Digital Signal Processing (Elsevier Ltd.), Journals of Neurocomputing (Elsevier Ltd.), Neural Networks (Elsevier Ltd.), International Journal for Light and Electron Optics (Optik) (Elsevier Ltd.), The Visual Computer (Springer), Journal of Electronic Imaging (SPIE), Journal of Optical Engineering (SPIE), IEICE Journal Electronics Express (ELEX) and ECTI Transactions on CIT (ECTI Thailand). As a technical reviewer of over 40 international/national conferences since 2006, he has been assigned to review over 130 proceeding papers. He has participated in more than 8 projects and research programmed funded by public and private organizations. He works in the field of signal processing and multidimensional signal processing, specializing, in particular, on Image/Video Reconstruction, SRR (Super-Resolution Reconstruction), Compressive Sensing, Enhancement, Fusion, Digital Filtering, Denoising, Inverse Problems, Motion Estimation, Optical Flow Estimation and Registration.

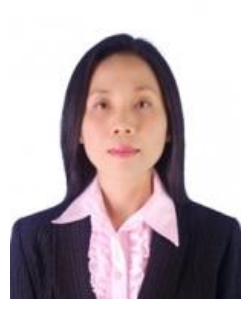

Kornkamol Thakulsukanant received the B.Eng. (Electrical Engineering) from Assumption University, Thailand in 1994, MSc. (Telecommunications and Computer Network Engineering) from London South Bank University, United Kingdom in 1997 and Ph.D. (in Electronic and Electrical Engineering) from Bristol University, United Kingdom in 2009 respectively. She served as a full-time lecturer at Faculty of Science and Technology, Assumption University since 1998 until 2014 and she has served as full-time lecturer at School of Management and Economics, Assumption University where she has been currently an Assistance Professor (in IT) since 2014. She works in the field of Digital Signal Processing (DSP) and Digital Image Processing (DIP), specializing, in particular, on Digital Image Reconstruction/Enhancement. 